\section{Classroom \\ behaviour, language competence, and the acceptance of children with Down syndrome by their mainstream peers}

\author{
Glynis Laws,
}

\author{
Department of Psychology, University of \\ Surrey, U.K.
}

\author{
Maura Taylor, Susan Bennie \\ and Sue Buckley \\ Department of Psychology, University of \\ Portsmouth, U.K.
}

\begin{abstract}
This study investigated the popularity of children with Down syndrome with their peers in mainstream classrooms using established sociometric techniques. The classroom behaviour of 16 children with Down syndrome aged 8 to 11 years were assessed and the relationship between these behaviours and acceptance investigated. For comparison, the relationship between classroom behaviour and acceptance of 122 typically developing children from the same classes was examined. The majority of the children with Down syndrome were found to enjoy average levels of acceptance in the class. Although behaviour problems were significantly worse in the children with Down syndrome, poor behaviour did not influence the other children to reject them. There was a different picture for typically developing children where there was a strong relationship between behaviour and peer acceptance. Language skills were also assessed for the children with Down syndrome. The children's language skills were not related to their popularity with the other children. Neither problem behaviours nor language difficulties influenced friendships in or out of the classroom for the children with Down syndrome.
\end{abstract}

\footnotetext{
Acknowledgements

The data for this research were collected by Susan Bennie and Maura Taylor for their dissertations for the BSc in Psychology at the University of Portsmouth. The authors would like to thank the children and teachers at the Hampshire schools which participated in the study.
}

(C) 1993, 1999. The Down Syndrome Educational Trust Down Syndrome Research and Practice

1996, 4 (3) 100-109
Introduction

\section{Mainstream education}

Since the publication of the Warnock report (1978), and the Education Act (1981) it has been government policy to integrate children with Down syndrome into mainstream schools. While this policy is some way from being implemented in many areas of the U.K., in Hampshire, where the study reported here took place, there has been a significant move towards mainstream placements for the children. It is important to understand how the children are accepted by their peers and whether any aspects of their behaviour influence this acceptance.

The move towards mainstream education for children with learning disabilities was in response to several factors. Mainstream classrooms provide a richer language environment in which to develop communication skills (Guralnick, 1984), and to develop peer relationships (Guralnick, 1978). It was expected that sociable behaviours would be increased by the imitation of typically developing children (Guralnick, 1984), and by the opportunity to develop friendships at school with children from the same neighbourhood (Byrne, Cunningham \& Sloper, 1989). Also, mainstreaming provides typically developing children with experience of learning disabilities and so may promote greater tolerance and understanding of the variability in human abilities (Gottlieb \& Leyser, 1981; Stainback \& Stainback, 1985). Schools are a microcosm of society and reducing stigma attached to disabled children is a major goal of mainstreaming policy (Falvey, 1995).

\section{Peer relations}

Peer relationships are important to cognitive and social development (Piaget, 1932). They influence the development of self (Sullivan, 1953), facilitate cognitive development (Perret-Clermont, 1980) and contribute to the development of communicative competence (Guralnick, 1981). A child's social behaviour and personal-social effectiveness is largely governed by the experience of social interactions with peers (Baumrind, 1972; Charlesworth \& Hartup, 1967) and the foundations of all adult relationships may originate in childhood (Duck, 1983).

The measurement of peer popularity/acceptance Sociometric methods for studying popularity and unpopularity have been developed over time based on the work of Moreno (1934). The method involves rating children according to the number of positive nominations received when classmates are asked "who do you most like?", and may include a negative rating element by asking "who do you least like?" and subtracting this from the positive nomination (Asher \& Hymel, 1981; Gronlund \& Anderson, 1957). This formula distinguishes between children who are actively rejected by their peers and those who are simply not nominated as liked. Using such methods, children can be classified as popular or unpopular based on a procedure by Coie and Dodge (1983). Alternatively, children may be classified into three social status groups defined according to a study by Parker and Asher (1993) as highly accepted, averagely accepted and low accepted or rejected children.

In typically developing children, relationships have been established between these status groups and behaviour. The behavioural correlates of rejected status include aggression, rule violations, hyperactivity and disruptiveness, with 
aggression more associated with the rejection of boys (Coie, Dodge \& Kupersmidt,1990). In elementary school, physical aggression gives way to verbal aggression and disruption of classes as children get older. There is also a relation in middle school between social withdrawal and rejection, particularly for girls. However, all these behaviours could as easily be consequences of rather than causes of rejection.

\section{Peer relations of children with learning disabilities} Adolescents with moderate learning disabilities in special schools have similar social structures to typical youngsters (Siperstein and Bak, 1989). However, Guralnick (1984) suggests that in specialised settings a highly atypical path of social development is followed with children reaching an asymptotic level of interaction with peers during early preschool and remaining there until the early elementary school years.

Field, Roseman, Destefano and Koewler (1981) found that mainstreaming had no substantial effect on social and play interactions of the developmentally delayed. Guralnick (1981) found reduced levels of inappropriate play for the severely delayed in mainstream settings, but believed the effects of integration may be superficial and that extensive social separation occurs during more elaborate, more important forms of social play. Typically developing children behaved more like adults or older siblings in their communication with disabled friends so that co-equal interactions, said to be necessary for promoting peer relations, may not be achieved in mainstream programmes.

Much of the research literature suggests that learning disabled children are less accepted in mainstream classes. Weiner (1987), in a meta analysis of 19 studies, found that 15 of them showed that the learning disabled had lower peer status than the non learning disabled. Weiner, Harris and Shirer (1990) found learning disabled children were less likely to be rated as popular and more likely to be rated as neglected and rejected. However, Kistner and Gatlin (1989) found the majority of integrated learning disabled children were popular, with about one third of them neglected or rejected. Perlmutter, Crocker, Cordray and Garstecki (1983) also found a substantial number of the learning disabled to be popular, while Dudley-Marling and Edmiason (1985) suggest most learning disabled children enjoy relatively neutral social status.

Despite this variability in group findings, one consistent result is that some learning disabled children are accepted by their peers (Kistner \& Gatlin 1989). Research has attempted to investigate what distinguishes those who are more accepted than others, as well as why there may be less acceptance generally of this group. In typically developing children, there are consistent relationships between intelligence, academic achievement and peer status (Hartup 1970). Horowitz (1981) found IQ and peer acceptance also correlated amongst the learning disabled and that significant differences between the peer status of learning disabled and typically developing children were eliminated when IQ was co-varied. Kistner and Gatlin (1989) found no relationship between IQ or academic achievement and peer status, and no difference in these factors between popular or rejected learning disabled children.

Aggression and withdrawal are negatively correlated with positive peer evaluation and positively correlated with negative evaluation (Kistner \& Gatlin, 1989). Gresham and Reschly (1986) also found that peer rejection was positively correlated with peer ratings of dependence, unassertiveness and passivity. These relationships may be similar to those discovered between peer acceptance and behaviour for typically developing children (Coie, Dodge \& Kupersmidt, 1990) and further investigations of the relationship between classroom behaviour problems and peer relations of learning disabled children may be worthwhile.

\section{Behaviour of children with Down syndrome}

The evidence regarding the prevalence of behaviour problems within the Down syndrome population is mixed. Differences in the severity of intellectual impairment, chronological age, gender distribution and method of sample recruitment may all affect research findings, so caution is required in interpreting results (Cuskelly \& Dadds 1992). A stereotype exists of the child with Down syndrome as good tempered, affectionate, placid and cheerful (Tredgold 1949, Domino 1965, Gibson 1978); Gunn and Berry (1985) describe individuals with Down syndrome as easy to manage. However, Gath (1972) found the majority of parents complained of serious management problems; Gath and Gumley (1984) found 8 out of 14 boys and 3 out of 8 girls suffered behaviour problems. Byrne et al (1989) reported that $44 \%$ of mothers of children with Down syndrome found behaviour problems the hardest thing to cope with. Ganiban, Wagner and Ciccheti (1990) have concluded that the old stereotype of "easy temperament" and temperament homogeneity is not supported and that within the Down syndrome population a variety of temperament profiles and range of characteristics exist.

Many of the behaviour problems described by researchers have been attributed to attention deficits. Green, Dennis and Bennets (1989) found evidence of variation in attention related behaviours within Down syndrome which was not a simple reflection of lower mental age. Children with Down syndrome may have more problems overall than their siblings and significantly more attention/immaturity problems (Cuskelly \& Dadds, 1992; Gath \& Gumley, 1987). Pueschel, Bernier and Pezzullo (1991) found more hyperactivity, mainly due to lack of concentration, attention seeking and impulsivity. These are all problems associated with peer rejection in typically developing children.

The importance of language in peer relationships The slow development of motor, perceptual, cognitive, language and communication skills may all lead to difficulties in developmentally delayed children since these functional areas all underlie social competence (Serafica, 1990). The language difficulties experienced by many children with Down syndrome could therefore place them at a social disadvantage. Language development tends to be delayed relative to typically developing children and in relation to other cognitive skills. Language comprehension is generally better than language expression which rarely exceeds that of the typical three to five year old (Chapman, 1995; Fowler, 1990). In addition, individuals with Down syndrome experience complex speech difficulties leading to problems of intelligibility (Hamilton, 1993).

The importance of language in sustaining peer relations becomes clear when considered in relation to the developmental course that peer relations take. Gottman and colleagues (Gottman, 1983; Gottman \& Mettetal, 1986; 
Gottman \& Parkhurst, 1980; Parker \& Gottman, 1989) characterise the development of peer relations in terms of three periods. In early childhood, from age 3 to 7 years, children may engage in parallel play which places few social demands on children. However, fantasy play offers children more satisfaction but places greater demands on their communication and social skills. Goldstein and Gallagher (1992) suggest that, for this reason, children with limited language skills may be less valued partners for this important fantasy play.

From ages 8 to 12 years, the main theme of peer relationships is group inclusion; it is important to be part of a group and to avoid rejection. Parker and Gottman (1989) suggest that verbal behaviours such as gossip and teasing are important in forming social groups, and many group norms deal with the content and style of talking. Poor language skills will make it difficult for children to join in with this sophisticated verbal interaction (Goldstein \& Gallagher, 1992). Similarly, during adolescence, from ages 13 to 18 years, the highly verbal activities which characterise this age will be difficult for those with poor language skills.

Brooks-Lynn and Luciano (1985) have highlighted a role for expressive language deficits in poor peer interaction. However, language deficits may not inevitably reduce the potential for successful peer relationships. Carpenter (1995) investigated the attitudes of his daughter's 7 to 8 year old classmates. She has Down syndrome and, although the comments of her classmates make it clear that they were very aware of her language difficulties, there was no suggestion of any lack of acceptance.

\section{The roles of behaviour and language skills in peer acceptance}

The literature reviewed suggests that peer acceptance of children with Down syndrome in mainstream classes could be affected by classroom behaviour and/or language skills. The study reported here investigated this relationship by comparing the levels of popularity of typically developing children to the levels enjoyed by children with Down syndrome in the same classes. The study also investigated teachers' behaviour ratings for the children and examined the relationship between behaviour problems and popularity. Based on earlier research, it was expected that the children with Down syndrome would be rated by their teachers as having more behaviour problems than the typically developing children, and that there would be an association between behaviour problems and peer acceptance for the children with Down syndrome and the typically developing children. Measures of expressive language and language comprehension were also used to investigate possible associations between language competence and peer acceptance. We expected that the children with Down syndrome may enjoy less popularity overall, and that they could be chosen less often as companions than the other children. Given the importance of language skills in peer interactions, we expected to find that children with better language skills would enjoy more popularity than those with poor skills.

\section{Method}

\section{Pilot study}

A pilot study was carried out with members of a mainstream class which included no children with learning disabilities. 5 girls and 5 boys aged from 7 to 8 years were interviewed. All were able to understand and respond to questions about which three children they liked the most and which they least liked. The question about the most liked children yielded the most nominations with children tending to give more than the three names they were asked for. It was decided to ask for five names in the main study; the number of negative nominations was not increased as children were most hesitant with their responses to this question.

In addition to the questions designed to yield a popularity rating, a range of other questions that were thought to be informative about children's companions was also piloted. From this range, the three questions that were most readily understood and answered with the greatest ease were chosen for the main study. These questions are items from a companionship scale (Mendelson, Aboud \& Lanthier 1994) and ask who the children like to be with at lunch time or in the playground, or who they would like to invite home.

\section{Main study}

\section{Participants}

Consent was obtained from head teachers following an explanatory letter from the Sarah Duffen Centre which has a role in providing educational advice to the schools and is conducting longitudinal research in these schools in which the children with Down syndrome are involved. A subset of 16 children from this project took part in the study.

The mainstream schools are all within the same education authority and, in each case, the child with Down syndrome was the only such child in their class. The group included eight boys and eight girls whose ages ranged from 8 years 4 months to 11 years (Mean $=9$ years 6 months). Three of the girls were a chronological year older than their classmates and five were the same age. Four of the boys were a chronological year older than their classmates and the other four were with same age classmates. Some of the classes had been together for one year only; in others, the children had known most of the children in their class from pre-school nursery groups.

Within each class, children of the same gender as the child with Down syndrome were selected for the study. In total, the typically developing children consisted of 125 boys and 101 girls. One class of boys contained a mixed age group with one 5 year old and ten 6 year olds. Apart from this class, the boys ranged in age from 7 to 11 years (Mean $=8$ years 3 months). Amongst the girls there was one 6 year old child but the other children ranged in age from 7 to 10 years (Mean $=8$ years 2 months) .

\section{Measures}

Popularity measure

The popularity/acceptance score was obtained by interviewing the children with Down syndrome and the other children selected for the study from their class about their friendships.

The questions posed to the children were:

Q1. Out of the girls/boys in your class, who are the 5 you like most?

Q2. Who is your very best friend in the class? 
Q3. Who are the 3 girls/boys you least like?

Q4. Which 3 girls/boys would you choose to sit with at lunch time?

Q5. Which 3 girls/boys would you choose to play with in the playground?

Q6. Which 3 girls/boys would you most like to invite home after school?

Negative nominations in response to question 3 were subtracted from positive nominations in response to question 1 and the scores were standardised to allow for differing class sizes (Coie \& Dodge 1983, Musun-Miller 1990). Earlier work shows this method has yielded reliability measures of between 0.46 to 0.88 over a twelve week period (Coie, Dodge \& Coppotelli 1982) which seems reasonable given that some degree of changes of friendships could be expected with children of the age studied.

\section{Behaviour measure}

The Conners Teacher Rating Scale (Conners, 1969) was used to measure classroom behaviour. Each of 39 items are rated on a scale of "not at all", "just a little", "pretty much" and "very much" with responses assigned scores of 0 - 3 respectively. A total score can be obtained by summing across all items. Factor analysis shows the scale has six factors: Hyperactivity, which includes items such as "inattentive, easily distracted" or " disturbs other children"; a Conduct factor, which includes items such as "quarrelsome", "destructive" or "teases or interferes with other children"; an Emotional factor which includes items such as "often cries", "temper outbursts"; an AnxiousPassive factor associated with items such as "lacks leadership", "submissive", "shy"; an A-social factor including items like "isolates self from others" and "no sense of fair play"; and a Daydream scale which includes items such as "fails to finish things he starts" and "daydreams".

\section{Language measures (obtained from children with Down syndrome).}

Test for Reception of Grammar (TROG) (Bishop, 1983). This is a test of grammar understanding. Each item involves the selection of the correct picture to match a phrase or sentence spoken by the examiner.

British Picture Vocabulary Scale (BPVS) (Dunn \& Dunn, 1982). This test measures receptive vocabulary by asking the child to select the correct picture to match each item spoken by the examiner.

Mean Length of Utterance (MLU). A sample of a minimum length of 50 utterances was collected. MLU was calculated in accordance with Miller and Chapman's (1981) adaptation of Brown's (1973) formula and used as a measure of grammatical complexity.

Unintelligibility score. A crude measure of intelligibility was calculated by counting the number of unintelligible utterances in the sample of 50 used to measure MLU.

\section{Procedure}

The interviewers were introduced to each class and the children were told they were interested in children's friendships and would like to ask all the boys/girls in the class questions about who they liked and why they liked them. The children were called out of the class individually and interviewed in a quiet area of the school. The order in which the children were called was according to the class register. No indication of any particular interest in the child with Down syndrome was given.

At the start of the interview, the interviewer explained the type of questions to be asked. The child was told they did not have to participate if they did not want to, and also told that if there were any particular questions they did not want to answer they could move on to the next question. All the children agreed to participate. The popularity questions were asked and responses recorded. Following each question the responses were written on a blank piece of paper in view of the child. Any reasons given for the selection were also written down along with any other comments made about the questions. At the end of the interview, the children were thanked for helping, told that their answers would not be discussed with anybody else, and asked not to talk about their answers with their classmates.

A conversation with each child with Down syndrome was recorded to obtain a language sample. A box of toys, books and postcards provided materials to elicit conversation where necessary. The conversation continued until a minimum of 50 utterances had been recorded. The recordings were transcribed and agreed by two listeners. Receptive language measures using the TROG and BPVS were collected on another visit to school for use in another study.

The class teacher was asked to complete the behaviour questionnaire for each of the children interviewed and to return them by post.

\section{Results}

\section{Social status groups}

A popularity score was calculated for each participant by subtracting the number of negative/least liked ratings from the number of positive/most liked ratings. To allow for differences in class size, scores were converted to $z$ scores (Coie et al, 1982). The scores were used to divide the children into three social status groups. A high acceptance score was defined as a $z$ score of at least +1 , and a low acceptance score was defined as a $z$ score of -1 or lower, with children between these two points being classified as an average acceptance group, following other users of this methodology (Asher \& Dodge, 1986; Musun-Miller, 1990). The opportunity to include five children in the "most liked" group in the procedure used in this study means that these results may be slightly skewed in favour of higher popularity for our participants compared with earlier studies.

The frequency and distribution of popularity/acceptance scores for the group of children with Down syndrome were compared with those for the typically developing children (see Table 1).

The children with Down syndrome appeared most often in the average acceptance group with only a small proportion identified as either highly or poorly accepted. A greater proportion of the typically developing children appeared in high and low acceptance categories but chi-square analysis shows no significant association between group and acceptance. Further analysis revealed no significant differences in acceptance between boys and girls with Down syndrome or boys and girls in the typically developing group. 
Table 1: Frequencies and percentages of children in each social status group classified according to popularity scores for each group of children

\begin{tabular}{|lll|}
\hline & $\begin{array}{l}\text { Typically Developing } \\
(\mathrm{n}=226)\end{array}$ & $\begin{array}{l}\text { Down Syndrome } \\
(\mathrm{n}=16)\end{array}$ \\
Acceptance & $41(18 \%)$ & $1(6 \%)$ \\
High & $148(66 \%)$ & $13(81 \%)$ \\
Low & $37(17 \%)$ & $2(13 \%)$ \\
\hline
\end{tabular}

Table 2: Mean scores of typically developing children and those of children with Down syndrome on Conners Teachers Rating Scales.

\begin{tabular}{|c|c|c|c|c|}
\hline & $\begin{array}{l}\text { Typically } \\
\text { Developing } \\
\text { Children } \\
n=122\end{array}$ & $\begin{array}{l}\text { Children with Down } \\
\text { Syndrome } \\
\mathrm{n}=16\end{array}$ & $\mathrm{U}(16,122)$ & $\begin{array}{l}\text { Significance } \\
\text { level }\end{array}$ \\
\hline \multicolumn{5}{|l|}{ Scale } \\
\hline Hyperactivity & 12.24 & 21.94 & 494 & $\mathrm{p}<0.001$ \\
\hline Conduct & 5.72 & 10.5 & 518.5 & $p=0.001$ \\
\hline Emotional & 4.37 & 9.13 & 457 & $\mathrm{p}<0.001$ \\
\hline Anxious/Passive & 4.5 & 5.31 & 789.5 & NS \\
\hline A-social & 2.3 & 2.31 & 805 & NS \\
\hline Daydream & 2.28 & 8.5 & 697.5 & $p<0.05$ \\
\hline Overall score & 31.4 & 52.75 & 515 & $p=0.001$ \\
\hline
\end{tabular}

There was no relationship between popularity ratings and the age of the children.

\section{Behaviour measures}

Although questionnaires were completed for all the children with Down syndrome, some teachers did not complete the questionnaires for all the other children in the class. Data were obtained for six complete classes of boys and three complete classes of girls plus another three classes where the teachers had completed the form for a subset of the children. The analysis which follows is based on data from 122 children (78 boys and 44 girls) plus the children with Down syndrome.

The Conners Teacher Rating Scale yielded a total score as well as scores on the six subscales described above. For each of these measures, Mann-Whitney $U$ tests were used to compare the scores of children with Down syndrome with those of the typically developing group (see Table 2 ).

Table 2 shows overall differences in behaviour between the children with Down syndrome and their typically developing classmates. They are perceived to have greater problems in the areas of hyperactivity, conduct and emotional problems, the differences in these areas being highly significant. There are also significant differences in the levels of daydreaming behaviour. The Anxious/Passive and A-social scales did not distinguish the two groups.

\section{The association between classroom behaviour and social status}

Table 3 shows the Conners Teacher Rating scores for overall behaviour and for the subscales for each social status group for the typically developing children.

Kruskall Wallis one way analysis of variance was used to investigate the differences between behaviour scores for the three acceptance groups. For each type of behaviour problem, with the exception of Anxiety, there were clear differences between the groups. The most popular or accepted children had fewest problems whilst the rejected children in the low acceptance group had the most severe behaviour problems.

It was not possible to undertake a similar analysis for the children with Down syndrome since there were few of them in our sample and the majority were placed in the average acceptance group. However, it is worth noting that for every type of problem except daydreaming, the behaviour scores of the children with Down syndrome show more severe problems than the typical children, even those who are poorly accepted by their peers (compare Table 2 means for children with Down syndrome with the low acceptance means in Table 3). This suggests that, although classroom behaviour differentiates popular and unpopular children in the general population, there appears to be no similar relationship between behaviour problems and popularity 
Table 3: Mean behaviour scores for high, average and low acceptance groups for the typically developing children.

\begin{tabular}{|lllll|} 
& & & & \\
& High & Average & Low & $\chi(p)$ \\
& Acceptance & Acceptance & Acceptance & \\
Hyperactivity & 9.52 & 14.8 & 18.7 & $7.18(p<0.05)$ \\
Conduct problems & 4.04 & 6.26 & 8.88 & $5.41(p<0.05)$ \\
Emotional & 2.96 & 5.21 & 6.08 & $5.59(p<0.05)$ \\
Anxious/Passive & 3.36 & 4.84 & 4.38 & $3.49(\mathrm{NS})$ \\
A-Social & 1.28 & 2.08 & 4.17 & $8.25(p<0.05)$ \\
Daydreaming & 1.48 & 2.43 & 3.17 & $6.80(p<0.05)$ \\
Overall scores & 22.44 & 33.84 & 45.3 & $7.27(p<0.05)$ \\
& & & & \\
\hline
\end{tabular}

Table 4: Language profiles of the children with Down syndrome: TROG, BPVS and MLU mean age equivalent scores and mean unintelligible utterances.

\begin{tabular}{|c|c|c|}
\hline & Mean & Range \\
\hline TROG & 4y $7 m$ & $4 y 0 m$ to $5 y 6 m$ \\
\hline BPVS & $4 y 11 \mathrm{~m}$ & $3 y 7 m$ to $6 y 7 m$ \\
\hline MLU & $3 y 4 m$ & $1 \mathrm{y} 8 \mathrm{~m}$ to $6 y \mathrm{~m}$ \\
\hline $\begin{array}{l}\text { No. unintelligible } \\
\text { utterances }\end{array}$ & 8.75 & $1-20$ \\
\hline
\end{tabular}

Table 5: Percentage of children receiving nominations as best friend.

\begin{tabular}{|llllllll|}
\hline & \multicolumn{7}{c|}{ Number of nominations received } \\
& None & One & Two & Three & Four & Five \\
& 43.3 & 33.9 & 17.3 & 3.1 & 1.6 & 0.8 \\
Boys & 37.4 & 42.4 & 15.2 & 4.0 & 1.0 & 0 \\
Girls & 75.0 & 0 & 25 & 0 & 0 & 0 \\
Boys with DS & 75.0 & 12.5 & 12.5 & 0 & 0 & 0 \\
Girls with DS & & & & & & \\
\hline
\end{tabular}

among the children with Down syndrome. This impression was confirmed by the use of Spearman's rho to investigate the correlation between the behaviour scores and popularity rating of the children with Down syndrome. There were no significant relationships between popularity and any of the Conners scale scores for this group.

\section{Language measures}

The TROG, BPVS and MLU scores for the children with Down syndrome were converted to age equivalent scores (see Table 4).
The MLU age equivalent scores were calculated using the regression equation derived from preschool data by Chapman, Ross and Seung (1993). Table 4 also shows the mean number of unintelligible utterances.

Correlations were calculated between the children's popularity scores and all language measures. There were no significant relationships between either expressive or receptive language abilities and the popularity of children with Down syndrome.

\section{Friendship}

The other questions asked in this study were concerned with friendship which is a rather different concept from popularity. It may be just as rewarding to have one special friend as to enjoy general classroom popularity.

All of the participants were included in this part of the analysis. The children were asked who was their very best friend. Four of the children with Down syndrome received best friend nominations, two girls and two boys. Of these, three were nominated twice. A comparison with typically developing children is shown in Table 5.

The results suggest that few of the children with Down syndrome enjoy the status of being someone else's best friend. Only about $25 \%$ of the children were nominated as best friends compared with about $60 \%$ of the typically developing children.

Finally, the children were asked who they liked to sit with at lunch, to play with in the playground and to invite home after school. Table 6 shows the number of times children with Down syndrome were nominated compared with their classmates. 
Table 6: Percentage of children chosen as companions by their classmates

\begin{tabular}{|c|c|c|c|c|c|c|c|}
\hline \multirow{2}{*}{ "Sit with at lunch" } & \multicolumn{5}{|c|}{ Number of nominations received } & \multirow{2}{*}{\multicolumn{2}{|c|}{ Five or more }} \\
\hline & None & One & Two & Three & Four & & \\
\hline Children with DS & 100 & 100 & 050 & 10 & 0 & 0 & \\
\hline Other children & & 15.9 & 20.8 & 26.5 & 12.8 & 15.0 & 8.9 \\
\hline \multicolumn{8}{|c|}{ "Play in the playground" } \\
\hline Children with DS & 25.0 & 25.0 & 18.8 & 18.8 & 12.5 & 0 & \\
\hline Other children & & 15.9 & 21.2 & 25.7 & 15.9 & 11.9 & 9.3 \\
\hline \multicolumn{8}{|l|}{ "Invite home" } \\
\hline Children with DS & 56.3 & 12.5 & 6.3 & 6.3 & 18.8 & 0 & \\
\hline Other children & & 18.1 & 21.2 & 23.9 & 17.3 & 12.8 & 6.7 \\
\hline
\end{tabular}

children had fewest problems of any kind, with those in the average group having significantly more problems, and those in the rejected category having significantly more behaviour problems again.

Interestingly, this association between behaviour and peer acceptance was not evident for the children with Down syndrome, even though their behaviour was worse even than that of the rejected group of typically developing children. There could be a number of reasons for this.

Although there was little difference in the number of times the typical children and the children with Down syndrome were chosen as playground companions, there was a more marked difference between the groups on the other two questions. Just under half of the children were never selected as a lunchtime companion and over half of them were never invited to a schoolmate's home after school. Mann-Whitney $\mathrm{U}$ tests confirmed that the differences observed for these two questions were significant: for "lunchtime companions", $U(16,226)=1207.7, p<.005$; for "invitations home", $U$ $(16,226)=1182.5, p<.02$.

Spearmans rank order correlation coefficient was used to investigate the relationship between the number of times children were selected as companions in the three situations and their behaviour and language. A Bonferroni adjustment of the probability level accepted was used to take account of the large number of correlations. There were no significant correlations between the number of times the children were selected as companions and their scores on the language or behaviour measures.

\section{Discussion}

The study has revealed some interesting similarities and differences between children with Down syndrome and their classmates in mainstream classrooms. The investigation of popularity or acceptance showed that children with Down syndrome were generally no less popular than the typically developing children. This differs from most previous research involving mainstreamed children with learning disabilities (Weiner et al 1990). It also differs from studies involving preschool children with Down syndrome who were observed as isolated within the mainstream nursery school environment (Sinson \& Wetherick 1981). The finding that most of the children with Down syndrome in our study enjoy average acceptance is similar to that of Dudley-Marling and Edmiason (1985) who concluded that most learning disabled have relatively neutral social status; certainly few of the children in our sample were either highly popular or rejected.

The investigation of behaviour problems showed that the children with Down syndrome had significantly more problems of all kinds except Anxious/Passive behaviour or A-social behaviour. For the typically developing children, our results confirmed the association between classroom behaviour and acceptance predicted by earlier research (Coie, Dodge \& Kupersmidt, 1990). The highly accepted
Lewis and Lewis (1987) suggest that classmates have sympathetic attitudes towards the severely learning disabled and that they are viewed as qualitatively different from the group of "problem" children who would normally be found in the rejected category. These authors found the severely learning disabled were seen as having no responsibility for and no control over their condition and so were viewed more positively than a group of low achievers who were seen as responsible for their own difficulties. It is also possible that other aspects of the personality or behaviour of the children with Down syndrome compensate for the problems. An investigation of pro-social behaviours might bring to light differences between the children with Down syndrome and other children with difficult behaviours who are generally rejected by their classmates.

The children were also asked about who they liked to spend time with inside or outside school. There was no significant difference between the groups for playing in the playground. This is also the time when children are most likely to engage in fantasy play for which Goldstein and Gallagher (1992) suggest poor language skills may limit children's value as play partners. Possibly poor spoken language does not limit potential for such play as long as communication can be maintained. Communication and language are quite separate (Sperber \& Wilson, 1986) and it is skill in the former that may be important for social interactions. The high levels of hyperactivity, conduct and emotional problems are evidently less of a hindrance to the other children in the playground environment than in class. However, it is also possible that these behaviours do not feature so much in the playground. Further research to investigate the situational factors associated with problem behaviours in this group would be useful.

Significantly fewer children with Down syndrome are chosen to sit with at lunch time. There could be practical reasons for this as some may receive supervision that singles them out so that the other children are not able to sit with them. Lewis and Lewis (1987) found the severely learning disabled were viewed as potentially "messy"; perhaps some of the children with Down syndrome were not as socially skilled at the dinner table as others and so were avoided.

The question of who to choose to invite home also resulted in significantly fewer nominations of children with Down syndrome. Even the most popular of these children, 
according to the acceptance measure used, was not chosen for an invitation. Parents may play a large part in determining such a choice. Lewis and Lewis (1987) found children worried about parental approval of the children with learning disabilities. Lewis (1995) found that adults have a poor understanding of learning disability. Further study of the attitudes of the parents of the typically developing children could be illuminating. It may be important to brief other parents when the school is preparing to receive a child with Down syndrome. Parents may need some reassurance about their own ability to cope with a child before encouraging after school visits.

Few of the children with Down syndrome were chosen as best friends by their classmates; $25 \%$ of them enjoyed this status compared with about $60 \%$ of the typically developing children. This is a much lower proportion than some earlier studies; Byrne et al (1989) found that $58 \%$ of the children in their study had one special friend. However, the numbers of typically developing children reporting a special friendship was also relatively low in the present study compared with the figure of $76 \%$ reported by Newson and Newson (1976).

This study of peer acceptance of children in mainstream classes provides a relatively positive picture with the majority of the children enjoying average levels of acceptance and very few of them rejected. Although the children do show significantly higher levels of problem behaviours than their classmates it is encouraging that, while these will undoubtedly have negative effects on other aspects of their education and development, they do not cause their classmates to reject them. This is very different from the strong association found between behaviour problems and peer rejection in typically developing children. This difference could be seen in a negative light in that it suggests that the children with Down syndrome are perceived as different by their classmates. Lewis and Lewis (1987) discussed the sympathetic view of severely learning disabled taken by children, and Guralnick (1981) spoke of interactions between the children as being unequal and "older sibling like". A more positive way of viewing this is that if the children are going to need some form of support and supervision throughout their lives, then these mainstream children are learning to provide this with supportive "sibling like" relationships, and they themselves are gaining some insight and understanding of the needs of special children.

\section{References}

Asher,S.R. and Dodge,K. (1986). Identifying children who are rejected by their peers. Developmental Psychology, 22 , 444-449.

Asher,S.R. and Hymel,F. (1981). Children's social competence in peer relations: sociometric and behavioural assessment. in Wine, J.D. and Smye, M.D. (Eds.), Social Competence. New York: Guilford.

Baumrind,D. (1972). Socialisation and Instrumental Competence in Young Children In Hartup W.W. The Young Child: Reviews of Research. USA: Association for the education of the young child.

Bishop,D.V.M. (1983). Test for the Reception of Grammar (TROG). Department of Psychology, University of Manchester: Chapel Press.

Brooks-Lynn and Luciano, (1985). Social competence in young handicapped children: a developmental perspective. In M. Sigman (Ed.), Children with Emotional Disorders and Developmental Disabilities: Assessment and Treatment.
Orlando, Florida: Grume and Stratton.

Brown, R.(1973). A First Language: The Early Stages. London: Allen and Unwin.

Byrne,E.A., Cunningham,C.C. and Sloper, P. (1989). Families and Their Children with Down's syndrome: One Feature in Common. London: Routledge.

Carpenter,B. (1995). 'Tell me about Katie': Attitudes of mainstream 7-8 year olds to a peer with Down's syndrome. Down's Syndrome: Research and Practice, 3, 2, 45-52.

Chapman,R.S. (1995). Language development in children and adolescents with Down syndrome. In P. Fletcher and B. MacWhinney (Eds.), The Handbook of Child Language. Oxford: Blackwell.

Chapman,R.S., Ross,D.R. and Seung,H. (1993). Longitudinal language development in children and adolescents with Down syndrome. Paper presented at the American Speech-Language Association, University of Wisconsin-Madison, Wisconsin, USA, November 1993.

Charlesworth,R. and Hartup,W.W. (1967). Positive social reinforcement in the nursery school peer group. Child Development, 38, 993-1002.

Coie, J.D. and Dodge,K.A. (1983). Continuities and changes in children's social status: a five year longitudinal study. Merrill-Palmer Quarterly, 29, 261-282.

Coie,J.D., Dodge,K.A. and Cappotelli,H. (1982). Dimensions and type of social status: a cross age perspective. Developmental Psychology, 18, 557-570.

Coie,J.D., Dodge, K.A., and Kupersmidt, J.B. (1990) Peer group behaviour and social status In Asher,S.R. and Coie,J.D. (Eds), Peer Rejection in Childhood. New York: Cambridge University Press.

Conners,C. (1969). A teacher rating scale for use in drug studies with children. American Journal of Psychiatry, 126, 884-888.

Cuskelly,M. and Dadds,M. (1992). Behavioural problems in children with Down's syndrome and their siblings. Journal of Child Psychology and Psychiatry, 33 (4) 749-761.

Domino,G. (1965). Personality traits in institutional mongoloids. American Journal of Mental Deficiency, 69, 568570.

Dunn,L.M. and Dunn,L.M.L. (1982). British Picture Vocabulary Scale (short form). Windsor: NFER-Nelson Publishing Company.

Duck,S. (1983). Friends For Life: The Psychology of Close Relationships. Brighton: The Harvester Press.

Dudley-Marling,C.C. and Edmiaston,R. (1985). Social status of learning disabled children and adolescents: a review. Learning Disability Quarterly, 8, 189-204.

Education Act (1981). London: HMSO.

Falvey,M. (1995). Inclusion of students with disabilities in public schools and classrooms with their non-disabled peers In Nadel L. and Rosenthal D. (Eds), Down Syndrome: Living and Learning in the Community. New York: Wiley.

Field,T.M., Roseman,S., Destefano,L. and Koewler,J.H. (1981). Play behaviours of handicapped preschool children in the presence and absence of non-handicapped peers. Journal of Applied Developmental Psychology, 2, 49-58.

Fowler, A. (1990). Language abilities in children with Down syndrome: evidence for a specific syntactic delay. In C. Cicchetti and M. Beeghly (Eds.), Children with Down Syndrome: A Developmental Perspective. Cambridge: Cambridge University Press.

Ganiban,J., Wagner,S. and Cicchetti,D. (1990). Temperament and Down syndrome. In C. Cicchetti and M. Beeghly (Eds.), Children with Down Syndrome: A Developmental Perspective. Cambridge: Cambridge 
University Press.

Gath,A. (1972). The mental health of siblings of congenitally abnormal children. Journal of Child Psychology and Psychiatry, 13, 211-218.

Gath,A. and Gumley,D. (1986). Behaviour problems in retarded children with special reference to Down's syndrome. British Journal of Psychiatry, 149, 156-161.

Gath,A. and Gumley,D. (1987). Retarded children and their siblings. Journal of Child Psychology and Psychiatry, 28 (5), 715-730.

Gibson,D. (1978). Down's syndrome: The Psychology of Mongolism. London: Cambridge University Press.

Goldstein,H. and Gallagher,T.M. (1992). Strategies for promoting the social-communicative competence of young children with specific language impairment. In Odom, S.L., McConnell, S.R. and McEvoy, M.A. (Eds.), Social Competence of Young Children with Disabilities: Issues and Strategies for Intervention. Baltimore: Brookes.

Gottlieb,J. and Leyser,Y. (1981). Friendships between mentally retarded and non-retarded children. In Asher S.R. and Gottman J.M. (Eds.), The Development of Children's Friendships. New York: Cambridge University Press.

Gottman,J.M. (1983). How children become friends. Monographs for the Society for Research in Child Development, 48(3, Serial No. 201).

Gottman,J.M. and Mettetal,G. (1986). Speculations about social and affective development: Friendships and acquaintanceship through adolescence. In J.M. Gottman and J.G. Parker (Eds.), Conversations of Friends: Speculation on affective development. New York: Cambridge University Press.

Gottman,J.M. and Parkhurst,J.T. (1980). A developmental theory of friendship and acquaintanceship processes. In W.A. Collins (Ed.), Minnesota Symposia on Child Development: Vol. 13: Development of Cognition, Affect, and Social Relations. Hillsdale, NJ: Lawrence Erlbaum Associates.

Green,J.M., Dennis,J. and Bennets,L.A. (1989) Attention disorder in a group of young Down's syndrome children. Journal of Mental Deficiency Research, 33, 105-122.

Gresham,F.M. and Reschly,D.J. (1986). Social skill deficits and low peer acceptance of mainstreamed learning disabled children. Learning Disability Quarterly, 9, 23-32.

Gronlund,N.E. and Anderson,L. (1957). Personality characteristics of socially accepted, socially neglected and socially rejected junior high school pupils. Educational Administration and Supervision, 43, 329-338.

Gunn,P. and Berry,P. (1985). The temperament of Down's syndrome toddlers and their siblings. Journal of Child Psychology and Psychiatry, 26, 973-979.

Guralnick,M.J. (1978). Early Intervention and the Integration of Handicapped and Non-handicapped Children. Baltimore: University Park Press.

Guralnick,M.J. (1981). The social behaviour of preschool children at different developmental levels: effects of group composition. Journal of Experimental Child Psychology, 31, 115-130.

Guralnick,M.J. (1984). The peer interactions of young developmentally delayed children in specialised and integrated settings In Field T., Roopnarine J.L. and Segal M.S. (Eds.), Friendship in Normal and Handicapped Children. Norwood, U.S.A: Ablex.

Hamilton,C. (1993). Investigation of articulatory patterns of young adults with Down's syndrome using electropalatography. Down's Syndrome: Research and Practice, 1, 1, 15-28.
Hartup,W.W. (1983). Peer Relations. In Mussen P.H. (Ed.), Handbook of Child Psychology Volume 4. New York: Wiley. Horowitz E. (1981). Popularity, decentering ability and role taking skills in learning disabled and normal children. Learning Disability Quarterly, 4, 23-30

Kistner,J.A. and Gatlin,D. (1989). Correlates of peer rejection among children with learning disabilities. Learning Disability Quarterly, 12, 133-140.

Lewis,A. and Lewis,V. (1987) The attitudes of young children towards peers with severe learning difficulties. British Journal of Developmental Psychology, 5, 287-292.

Lewis,A. (1995). Children's Understanding of Disability. London: Routledge.

Mendelson,M.J., Abound,F.E. and Lanthier,R.P. (1994). Kindergartners' relationships with siblings, peers and friends. Merrill-Palmer Quarterly, 40, 3, 419-430.

Miller,J.F. and Chapman,R.S. (1981). The relation between age and mean length of utterance in morphemes. Journal of Speech and Hearing Research, 24, 154-161.

Moreno,J.L. (1934). Who Shall Survive? A New Approach to the Problem of Human Interrelations. Washington: Nervous and Mental Disease publishing.

Musun-Miller,L. (1990). Sociometrics with preschool children: Agreement between different strategies. Journal of Applied Developmental Psychology, 11, 195-61.

Newson,J. and Newson,E. (1976). Seven Years Old in the Home Environment. London: Allen and Unwin.

Parker,J.G. and Asher,S.R. (1993). Friendship and friendship quality in middle childhood: links with peer group acceptance and feelings of loneliness and social dissatisfaction. Developmental Psychology, 29, 4, 611-621. Parker,J. and Gottman,J. (1989). Social and emotional development in a relational context. In T. Berndt \& G. Ladd (Eds.), Peer Relationship in Child Development. New York: John Wiley.

PerImutter,B.F., Crocker,J., Cordray,D. and Garstecki,D. (1983). Sociometric status and related personality characteristics of mainstreamed learning disabled adolescents. Learning Disability Quarterly, 6, 20-30.

Perret-Clermont,A. (1980). Social Interaction and Cognitive Development in Children. New York: Academic Press.

Piaget,J. (1932). The Moral Judgement of the Child. U.S.A.: Free Press.

Pueschel,S.M., Bernier,J.C. and Pezzullo,J.C. (1991). Behavioural observations in children with Down's syndrome. Journal of Mental Deficiency Research, 35, 502-511.

Serafica,F.C. (1990). Peer relations of children with Down syndrome In: Cicchetti, D. and Beeghly, M. (Eds.), Children With Down Syndrome: a Developmental Perspective. Cambridge University Press : New York.

Sinson,J.C. and Wetherick,N.E. (1981). The behaviour of children with Down's syndrome in normal playgroups. Journal of Mental Deficiency Research, 25, 113-117.

Siperstein,G.N. and Bak,J.J. (1989). Social relationships of adolescents with moderate mental retardation. Mental Retardation, 27, 5-10.

Sperber,D. and Wilson,D. (1986). Relevance: Communication and cognition. Oxford: Basil Blackwell.

Stainback,L.S. and Stainback,S. (1987). Facilitating friendships. Education and Training in Mental Retardation. March, 18-25.

Sullivan,H. (1953). The Interpersonal Theory of Psychiatry. New York:

Tredgold,A.F. (1949). A Textbook of Mental Deficiency. London: Bailliere.

Warnock,M. (1978). Special Educational Needs: Report of the Warnock Committee of Enquiry into the Education of 
Handicapped Children and Young People. Cmd. 7212. London: HMSO

Weiner,J. (1987). Peer status of learning disabled children and adolescents: A review of the literature. Learning Disabilities Research, 2, 62-79.

Weiner,J., Harris,P.J. and Shirer,C. (1990). Achievement and social-behavioural correlates of peer status in learning disabled children. Learning Disability Quarterly, 13, 2, 114127.

Address for correspondence:

Dr. Glynis Laws,

Department of Psychology,

University of Surrey,

Guildford,

Surrey GU7 2PW

U.K. 